\title{
Total airway obstruction during local anesthesia in a non-sedated patient with a compromised airway
} [Une obstruction totale des voies aériennes pendant une anesthésie locale chez un patient éveillé qui présentait déjà une obstruction respiratoire partielle]

Anthony M. H. Ho MD FRCPC FCCP, David C. Chung MD FRCA FRCPC, Edward W. H. To BDS MBbS FrCS, Manoj K. Karmakar MD FRCA

Purpose: To report a case of complete upper airway obstruction after topicalization with lidocaine in a completely conscious patient with partial upper airway obstruction.

Clinical features: A 69-yr-old man with a history of neck cancer and radiation presented for resection of recurrent neck tumour. No preoperative sedation was given. He had inspiratory and expiratory stridor but had no history of aspiration or swallowing problem. Phonation was distorted but effective. The surgeon was reluctant to perform an awake tracheostomy under local anesthesia. In preparation for a fibrescope-assisted orotracheal intubation, the non-sedated patient was given topical upper airway lidocaine during which he developed total airway obstruction and hypoxemia. He was immediately intubated with a fibrescope. His vocal cords were not edematous although the supraglottic structures appeared to be. The vocal cords were abducted and their movement was limited and not paradoxical. Tumour resection was uneventful upon successful tracheal intubation and general anesthesia. Tracheostomy at the end of the case was difficult, as expected. The patient tolerated the procedures and regained consciousness with no neurologic sequelae.

Conclusion: Dynamic airflow limitation associated with local anesthesia of the upper airway may lead to complete upper airway obstruction in a compromised airway. The main cause may be the loss of upper airway muscle tone, exacerbated by deep inspiration during panic.
Objectif : Présenter un cas d'obstruction complète des voies aériennes supérieures après pulvérisation de lidocaïne chez un patient tout à fait conscient mais souffrant déjà d'obstruction respiratoire partielle.

Éléments cliniques : Un homme de 69 ans aux antécédents de cancer du cou et de radiothérapie s'est présenté pour la résection d'une tumeur récurrente au cou. Aucune sédation préopératoire n'a été administrée. II présentait un stridor inspiratoire et expiratoire, mais n'avait pas d'antécédent de trouble d'aspiration ou de déglutition. La phonation était déformée mais efficace. Le chirurgien était réticent à réaliser une trachéotomie vigile sous anesthésie locale. Pendant la préparation de l'intubation orotrachéale fibroscopique, de la lidocaïne topique a été administrée dans les voies aériennes supérieures du patient éveillé chez qui s'est développée une obstruction totale des voies aériennes et de l'hypoxémie. Il a été immédiatement intubé avec un fibroscope. Ses cordes vocales n'étaient pas œdémateuses même si les structures supraglottiques semblaient l'être. Les cordes vocales étaient écartées et leur mouvement était limité mais non paradoxal. La résection tumorale s'est bien déroulée sous intubation trachéale réussie et anesthésie générale. Comme prévu, la trachéotomie a été difficile à réaliser à la fin de l'opération. Le patient a bien toléré les interventions et s'est réveillé sans séquelles neurologiques.

Conclusion : Une limitation dynamique du débit d'air associé à l'anesthésie locale des voies aériennes supérieures peut conduire à une obstruction complète des voies respiratoires supérieures en cas d'obstruction partielle préalable. La principale cause pourrait être la perte du tonus musculaire des voies respiratoires supérieures, exacerbée par l'inspiration profonde pendant les moments de panique.

From the Department of Anaesthesia and Intensive Care, The Chinese University of Hong Kong, Prince of Wales Hospital, Shatin; and the Oral and Maxillofacial Surgery Centre, St. Teresa Hospital, Kowloon, Hong Kong, China.

Address correspondence to: Dr. Anthony Ho, Department of Anaesthesia and Intensive Care, The Chinese University of Hong Kong, Prince of Wales Hospital, Shatin, NT, Hong Kong SAR, PRC., Phone: 852-2632-2735; Fax: 852-2637-2422; E-mail: hoamh@cuhk.edu.hk

This work is attributable to the Department of Anaesthesia and Intensive Care, The Chinese University of Hong Kong, Prince of Wales Hospital, Shatin, NT, Hong Kong SAR, PRC.

Funding: Locally funded by the Department of Anaesthesia and Intensive Care, The Chinese University of Hong Kong.

Financial disclosure: No financial interests involved.

Accepted for publication January 27, 2004.

Revision accepted May 14, 2004. 


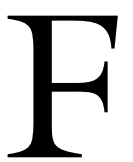

IBREOPTIC bronchoscope-assisted tracheal intubation with topical local anesthesia (LA) of the upper airway in an awake or sedated patient is considered by anesthesiologists as the ultimate, safe, non-surgical technique in difficult airway management. Failed awake/sedated fibreoptic intubation, sometimes after repeated attempts, occurs in $1.5 \%$ of cases ${ }^{1}{ }^{1}$ and does not carry the same negative implications as failed intubation in a paralyzed patient. As such, a "when in doubt, do an awake fibreoptic intubation" attitude is pervasive while pitfalls of the technique are rarely discussed in the literature or in airway guidelines and protocols. In head and neck surgical patients, difficult airways are common. When there is no surgical indication for a tracheostomy, the choice is often fibreoptic intubation with little or no sedation. However, the very objective of preserving spontaneous respiration can be abruptly denied in this group of patients. We report the case of a non-sedated patient with oral pathology who developed complete airway obstruction after lidocaine instillation onto the tongue and pharynx in preparation for fibreoptic intubation.

\section{Case report}

A 69 -yr-old $50-\mathrm{kg}$ man was to undergo excision of a recurrent squamous cell carcinoma on his lateral upper neck. Ten months prior, he had undergone tracheostomy and radical neck dissection, followed by high-dose radiation therapy. He had a remote history of cigarette and alcohol use. There was no known history of psychological or psychiatric problems, panic attacks, or sudden airway obstruction. On admission he was found to have hyponatremia, the etiology of which was unclear. His serum $\mathrm{Na}^{+}$had been as low as $123 \mathrm{mEq} \cdot \mathrm{L}^{-1}$ but had improved to $133 \mathrm{mEq} \cdot \mathrm{L}^{-1}$ on the day prior to surgery. He denied orthopnea or nocturnal sleep disturbances.

On examination, his scarred neck had contractures and a tracheostomy scar. The neck was slightly flexed and mobility was very limited. A mouth opening of $3.5 \mathrm{~cm}$ and a Mallampati grade 4 view without phonation (soft palate not visible) ${ }^{2}$ hinted at difficult laryngoscopy. He had inspiratory and expiratory stridor in both the supine and upright positions, and his speech was hoarse, though effective. There was mild pitting edema superficially, more so in dependent areas.

The day before surgery, we raised the issue of a tracheostomy under LA in lieu of endotracheal intubation. In the end, the problems associated with performing the procedure through scarred and irradiated tissues, and the immobility of the neck led to the decision against it.
In preparation for tracheal intubation, the nonsedated supine patient was given oxygen through a nasal cannula. With the surgeon and operating room nurses standing by, we gave atropine $0.2 \mathrm{mg}$ intravenously and instilled $2 \%$ lidocaine solution onto the tongue and pharynx followed by periodic gentle suctioning. ${ }^{3}$ A total of $7.5 \mathrm{~mL}$ of lidocaine $(<2.2$ $\mathrm{mg} \cdot \mathrm{kg}^{-1}$ ) had been used after nearly four minutes, at which time the patient developed complete airway obstruction. He pointed desperately in the direction of his mouth and chin. Mask ventilation was difficult, and pulse oximetry $\left(\mathrm{SpO}_{2}\right)$ dropped to the $60 \%$ range. A percutaneous cricothroidotomy resulted in bleeding and failed. Just as tracheostomy was about to begin, mask ventilation was successful in gradually improving the $\mathrm{SpO}_{2}$ to the mid-90\% range. At this point, an oral fibreoptic intubation with a $7-\mathrm{mm}$ internal diameter endotracheal tube could be performed. The oral soft tissues appeared swollen but the vocal cords and trachea were roughly normal. The unconscious patient's vocal cords were mainly abducted, exhibited limited movements that did not appear paradoxical. No thick mucous was seen. There was minimal reaction to the insertion of the tracheal tube. There was no hypotension or bronchospasm.

The patient received a tracheostomy upon completion of the tumour resection and repair. Not surprisingly, the procedure took much longer and caused more bleeding than usual. Postoperatively, the patient had no neurologic deficit. He recalled having difficulties breathing prior to losing consciousness.

\section{Discussion}

We report complete upper airway obstruction after upper airway topicalization with lidocaine in a nonsedated patient with a compromised airway. The cause was probably the loss of upper airway muscle tone, possibly exacerbated by collapse of upper airway structures during deep inspiratory efforts associated with panic, and by the preexisting swelling of his supraglottic structures. The swelling was likely the result of his primary disease, previous radiation treatment, and hyponatremia. The patient was alert when he pointed to where his obstruction was, and recalled much of the incident. Laryngospasm caused by the initial irritation of lidocaine on the cords (which later relaxed) could have led to panic and deep inspirations. The dose of lidocaine was likely not high enough to have caused excessive central nervous system depression. Lidocaine allergy is exceedingly rare, and the lack of systemic signs and symptoms made an allergic reaction improbable. Functional stridor ${ }^{4}$ and paradoxical vocal cord movement ${ }^{5}$ were unlikely because the glottic inlet, briefly 
observed during the passage of the bronchoscope, did not appear to be the cause of the obstruction.

Animal studies had revealed that receptors in the larynx help regulate laryngeal muscle activity, and LA of the larynx decreases upper airway muscle contractions during inspiration. ${ }^{6,7}$ In a study of alert volunteers, Liistro $e t a l .{ }^{8}$ found that after LA of the upper airway, maximum inspiratory flows and supraglottic airway pressures and flow were profoundly decreased. Similarly, Kuna et al. ${ }^{9}$ found a decrease of upper airway caliber after topical LA. Two mechanisms of this obstruction to airflow were offered. ${ }^{8,9}$ First, LA depresses laryngeal muscles and normal laryngeal function. Second, interference of lidocaine with the activity of specific receptors in the upper airway, especially at the laryngeal level, results in the loss of the normally coordinated opposition to the tendency of the upper airway mucosa to collapse during inspiration.

Complete airway obstruction after topical LA on and before instrumentation of the upper airway has also been reported by Shaw et al..$^{10}$ in a patient with a goiter and abnormal pharyngeal/laryngeal anatomy causing functional obstruction, and by White et al. ${ }^{11}$ in a patient who had inhaled cocaine. Airway obstruction during manipulation of a fibreoptic bronchoscope in patients with other head and neck pathologies has also been reported. ${ }^{12,13}$

How can we avoid this kind of crisis in the future? In the patient's history, the presence of stridor suggests a reduction in airway diameter of at least $50 \%{ }^{14}$ By itself, this degree of obstruction may not warrant the immediate elimination of awake fibreoptic intubation under LA as an option. More ominous is waking up in the middle of the night dyspneic and in panic, suggesting critical obstruction. ${ }^{14}$ Information on the obstruction may be obtained from the surgeon who may have performed an awake endoscopy. ${ }^{14}$ Gentler forms of anesthetizing the airway, such as nebulized lidocaine and systemic sedation, may not prevent the same mishap if indeed an important cause of airway obstruction is receptor desensitization. Sedation is not recommended in someone with a seriously compromised airway. ${ }^{1}$ Although experts have suggested inhalational induction in such situations, ${ }^{14}$ we caution that it may have many of the pitfalls of $i v$ sedation. A light anesthetic or sedation does not prevent coughing during instrumentation, and a deeper anesthetic results in airway obstruction caused by approximation of the soft palate to the posterior pharyngeal wall ${ }^{15,16}$ and posterior displacement of the tongue. A "gentle" awake laryngoscopy without LA is uncomfortable, induces coughing, and, when mouth opening and neck mobility are poor, would likely fail. Heliox may be useful in mild or moderate upper airway obstruction but not in complete obstruction or in the presence of hypoxia. ${ }^{17}$ Preoperatively, plain $x$-ray, computer tomography, magnetic resonance imaging, and ultrasonography can delineate static structural abnormalities. However, their routine use in such patients as part of airway evaluation is not established. Spirometry in the form of a flow-volume loop may detect dynamic airflow obstruction. There are, however, no imaging and spirometric criteria to predict severe or complete airway obstruction after LA. One could only speculate that failure of the patient to perform the flow-volume loop exercise or successful performance with alarming results would indicate critically compromised upper airway with very little margin of safety, and would suggest that there is a significant risk of complete airway obstruction after LA.

In summary, in this patient with severely compromised upper airway, the dictum "when in doubt, do an awake fibreoptic intubation" certainly did not apply, as topical LA precipitated total airway obstruction. Airway management in a patient with significant oral and head and neck pathology should be a joint decision between anesthesiologist and surgeon. In light of the difficulties of rapidly performing an emergency surgical airway in many patients, due consideration should be given to the performance of an elective awake tracheostomy under LA. In those cases in which the balance of evidence suggests that an attempt at awake oral or nasal tracheal intubation is justified, the personnel and equipment for an emergency surgical airway (in the form of a rigid bronchoscope and a double set-up) should be on standby in the operating room. Further observations and studies on the role of flow-volume loops and various imaging modalities in setting criteria for eliminating awake topical anesthesia as a first option and going straight to a surgical airway under LA are needed.

\section{References}

1 Heidegger T, Gerig HJ, Ulrich B, Schnider TW. Structure and process quality illustrated by fibreoptic intubation: analysis of 1612 cases. Anaesthesia 2003; 58: 734-9.

2 Juvin P, Lavaut E, Dupont $H$, et al. Difficult tracheal intubation is more common in obese than in lean patients. Anesth Analg 2003; 97: 595-600.

3 Chung DC, Mainland PA, Kong AS. Anesthesia of the airway by aspiration of lidocaine. Can J Anesth 1999; 46: 215-9.

4 Tousignant G, Kleiman SJ. Functional stridor diagnosed by the anaesthetist. Can J Anaesth 1992; 39: 286-9.

5 Arndt GA, Voth BR. Paradoxical vocal cord motion in 
the recovery room: a masquerader of pulmonary dysfunction. Can J Anaesth 1996; 43: 1249-51.

6 Mathew OP, Abu-Osba YK, Thach BT. Genioglossus muscle responses to upper airway pressure changes: afferent pathways. J Appl Physiol 1982; 52: 445-50.

7 van Lunteren E, Van De Graaff WB, Parker DM, et al. Nasal and laryngeal reflex responses to negative upper airway pressure. J Appl Physiol 1984; 56: 746-52.

8 Liistro G, Stanescu DC, Veriter C, Rodenstein DO, D'Odemont JP. Upper airway anesthesia induces airflow limitation in awake humans. Am Rev Respir Dis 1992; 146: 581-5.

9 Kuna ST, Woodson GE, Sant'Ambrogio G. Effect of laryngeal anesthesia on pulmonary function testing in normal subjects. Am Rev Respir Dis 1988; 137: 656-61.

10 Shaw IC, Welchew EA, Harrison BJ, Michael S. Complete airway obstruction during awake fibreoptic intubation. Anaesthesia 1997; 52: 582-5.

11 White MC, Reynolds F. Sudden airway obstruction following inhalation drug abuse (Letter). Br J Anaesth 1999; 82: 808.

12 Wulf H, Brinkmann G, Rautenberg M. Management of the difficult airway. A case of failed fiberoptic intubation. Acta Anaesthesiol Scand 1997; 41: 1080-2.

13 McGuire G, El-Beheiry H. Complete upper airway obstruction during awake fibreoptic intubation in patients with unstable cervical spine fractures. Can J Anesth 1999; 46: 176-8.

14 Mason RA, Fielder CP. The obstructed airway in head and neck surgery (Editorial). Anaesthesia 1999; 54: 625-8.

15 Nandi PR, Charlesworth CH, Taylor SJ, Nunn JF, Dore CJ. Effect of general anaesthesia on the pharynx. Br J Anaesth 1991; 66: 157-62.

16 Mathru M, Esch O, Lang J, et al. Magnetic resonance imaging of the upper airway. Effects of propofol anesthesia and nasal continuous positive airway pressure in humans. Anesthesiology 1996; 84: 273-9.

17 Ho AMH, Dion PW, Karmakar MK, Chung DC, Tay $B A$. Use of heliox in critical upper airway obstruction. Physical and physiologic considerations in choosing the optimal helium: oxygen mix. Resuscitation 2002; 52 : 297-300. 